\title{
Evaluation of a range of doses of ultraviolet irradiation to inactivate waterborne actinospore stages of Myxobolus cerebralis
}

\author{
R. P. Hedrick ${ }^{1, *}$, B. Petri ${ }^{2}$, T. S. McDowell ${ }^{1}$, K. Mukkatira' ${ }^{1}$, L. J. Sealey ${ }^{2}$ \\ ${ }^{1}$ Department of Medicine and Epidemiology, School of Veterinary Medicine, University of California, \\ One Shields Avenue, Davis, California 95616, USA \\ ${ }^{2}$ Trojan Technologies, 3020 Gore Road, London, Ontario N5V 4T7, Canada
}

\begin{abstract}
The ability of a range of doses of ultraviolet irradiation (UV) to inactivate the waterborne actinospore or triactinomyxon stages (TAMs) of Myxobolus cerebralis was evaluated by infectivity for juvenile rainbow trout Oncorhynchus mykiss. TAMs were UV-irradiated using a low pressure mercury vapour lamp collimated beam apparatus. All doses 40, 80, 120 and $160 \mathrm{~mJ} \mathrm{~cm}^{-2}$ were found to completely inactivate the TAMs as demonstrated by the absence of microscopic lesions, myxospores and parasite DNA detected by quantitative PCR (qPCR) among rainbow trout 5 mo post-exposure. In contrast, rainbow trout receiving the same concentrations of untreated TAMs $\left(1000 \mathrm{fish}^{-1}\right)$ developed clinical signs of whirling disease at 2 mo post-exposure and had severe microscopic lesions, high myxospore counts and high qPCR values when examined at 5 mo following exposure to the parasite.
\end{abstract}

KEY WORDS: Whirling disease - Ultraviolet irradiation · Fish hatchery · Disease control

\section{INTRODUCTION}

A major method to control whirling disease among hatchery-reared salmonids has been to implement procedures that minimize or eliminate contact between the parasite Myxobolus cerebralis and susceptible young trout or salmon (Hoffman 1970, 1990). The rearing and stocking of parasite-free trout by state, federal and commercial fish hatcheries also prevents one of the major methods by which whirling disease has spread to both farmed and wild trout populations (Nehring \& Walker 1996, Vincent 1996, Hedrick et al. 1998, Modin 1998). When hatchery water supplies contain infected salmonids and oligochaete hosts of M. cerebralis, disinfection of incoming water may be the only means to avoid the disease (Wagner 2002). Ultraviolet irradiation (UV) disinfection systems are commonly used for hatchery water supplies because they are effective at inactivating all classes of microbial pathogens, and do not use chemicals or leave chemical residuals in the water that can have adverse effects on the fish.

The earliest reports of the use of UV for control of whirling disease were those of Hoffman $(1974,1975)$. He found that UV treatments at calculated doses ranging from 18 to $112 \mathrm{mWs} \mathrm{cm}^{-2}\left(1 \mathrm{mWs} \mathrm{cm}{ }^{-2}\right.$ is equivalent to $1 \mathrm{~mJ} \mathrm{~cm}^{-2}$ ) provided partial to complete protection from Myxobolus cerebralis infections in tests conducted with rainbow trout Oncorhynchus mykiss receiving water with the then unknown infective stages which we now know are the actinospore or triactinomyxon (TAMs) stages of the parasite. These previously unknown waterborne stages were discovered by Wolf \& Markiw (1984), and this has led to the ability to propagate, isolate and accurately quantify levels of infectivity for controlled fish exposures. This allowed Hedrick et al. (2000) to conduct studies where known concentrations of TAMs were treated with different doses of UV and then evaluated by vital staining to 
develop an inactivation curve. These studies, using a collimated beam to deliver accurate UV doses, suggested that $1300 \mathrm{~mJ} \mathrm{~cm} \mathrm{~cm}^{-2}$ was required to inactivate $100 \%$ of the TAMs. Accordingly, higher UV doses were applied to TAMs in flow-through experimental exposure trials that completely protected juvenile rainbow trout from infections with $M$. cerebralis (Hedrick et al. 2000).

More recent studies on the effects of UV on UVsensitive parasites with waterborne cyst or spore-like stages (e.g. Cryptosporidium and Giardia) have demonstrated that vital staining may not be a good indicator of UV efficacy, as it may drastically underestimate parasite inactivation compared to more meaningful infectivity metrics (Bukhari et al. 1999, Craik et al. 2000). According to the United States Environmental Protection Agency (USEPA), 3 log inactivation of Cryptosporidium and Giardia can be safely achieved with UV doses of 12 and $11 \mathrm{~mJ} \mathrm{~cm}^{-2}$, respectively (Qian et al. 2004, Anonymous 2006). These recent findings with what were previously considered UV-resistant organisms prompted us to evaluate lower doses of UV than those used by Hedrick et al. (2000) to inactivate TAMs prior to exposures to juvenile rainbow trout. These studies were deemed important since the use of lower doses of UV would incur considerably less cost for large-scale water treatments (e.g. fish hatcheries) for inactivation of the waterborne stages of $M$. cerebralis.

\section{MATERIALS AND METHODS}

Production of TAMs. The TAMs of Myxobolus cerebralis were generated by an identical process to that described by Hedrick et al. (2000). The TAMs so prepared originated from myxospores from rainbow trout from the Mt. Whitney Hatchery, Independence, California, USA. The myxospores were added to susceptible populations of Tubifex tubifex obtained from the same location, and TAMs were harvested on the day of UV treatments and fish exposures.

Selection of UV doses. The UV doses selected for the current trials ranged from 40 to $160 \mathrm{~mJ} \mathrm{~cm}^{-2}$. This range was chosen to correspond to practical design doses employed in various UV disinfection applications. Drinking water systems are often designed for a UV dose of $40 \mathrm{~mJ} \mathrm{~cm}^{-2}$ which provides $4 \log$ reductions of the most resistant pathogens of epidemiological concern (Anonymous 1997, 2001, 2003a). Design doses for disinfection of reclaimed water for reuse purposes typically range from 50 to $100 \mathrm{~mJ} \mathrm{~cm}^{-2}$ (Anonymous $2003 \mathrm{~b}$ ), and a number of recent fish hatchery disinfection systems have been designed with UV doses of $120 \mathrm{~mJ} \mathrm{~cm}^{-2}$ (G. Vanderlaan pers. comm.). Our treat- ments went to higher UV doses of $160 \mathrm{~mJ} \mathrm{~cm}^{-2}$ to bracket this practical application range.

UV treatments of TAMs. A collimated beam apparatus was used for evaluating the efficacy of UV treatments for the inactivation of the TAMs of Myxobolus cerebralis. TAMs collected from experimentally exposed Tubifex tubifex cultures were harvested, enumerated, and diluted such that $50 \mathrm{ml}$ aliquots (the volume to be used in UV irradiations) would contain 2 $\times 10^{4}$ TAMs. Aliquots $(50 \mathrm{ml})$ of the diluted TAMs stock underwent UV irradiation using a low pressure mercury vapour lamp collimated beam device. A calibrated International Light 1700 radiometer was used to measure the irradiance of the UV light from the collimated beam. The UV transmittance at $254 \mathrm{~nm}$ (UVT) of the diluted TAMs suspension $\left(96 \% \mathrm{~cm}^{-1}\right)$ was measured with a P254C photometer in order to calculate the Water Factor. The Water Factor, Petri Factor, Divergence Factor and Surface Reflection Factor (2.5\%) were quantified and accounted for in determining UV dose (Bolton \& Linden 2003). Different UV doses were achieved by varying the irradiation time. Aliquots were constantly mixed with a magnetic stir bar during irradiations, so the positive/procedural controls consisted of stirring for the maximum irradiation time (approximately $16 \mathrm{~min}$ ) in the absence of UV light.

Exposures of rainbow trout to UV-treated TAMs. A total of 6 experimental groups each with 2 replicate sub-groups of 20 juvenile $\left(27 \mathrm{~d}\right.$ post-hatch at $\left.12^{\circ} \mathrm{C}\right)$ rainbow trout were prepared. The groups consisted of a negative control (no TAMs, no UV), a positive/procedural control (1000 TAMs fish ${ }^{-1}$, no UV), and $4 \mathrm{UV}$ treatments (1000 TAMs fish ${ }^{-1}$, UV doses of 40, 80, 120, and $160 \mathrm{~mJ} \mathrm{~cm}^{-2}$ ).

For TAMs exposures, 20 fish for each replicate subgroup were placed in $1 \mathrm{l}$ containers with $450 \mathrm{ml}$ of $15^{\circ} \mathrm{C}$ aerated well water. Treated or untreated TAMs aliquots $(50 \mathrm{ml})$ were added to each container. Because each $50 \mathrm{ml}$ aliquot contained $2 \times 10^{4}$ TAMs and each container had 20 trout, exposures were 1000 TAMs fish $^{-1}$. Each sub-group was exposed for $1 \mathrm{~h}$ with aeration, and then transferred to 201 aquaria receiving $15^{\circ} \mathrm{C}$ well water at a rate of $3.01 \mathrm{~min}^{-1}$. The fish were fed a commercially available trout diet at approximately $2 \%$ body weight $\mathrm{d}^{-1}$.

Assessments of whirling disease among exposed rainbow trout. All fish were observed for clinical signs of whirling disease throughout the experimental time course. As part of a different study, 5 fish were removed from each replicate sub-group aquarium at $10 \mathrm{~d}$, and 2 and 3 mo post-exposure. In the current study, the presence of whirling behavior and or a blackened tail region were recorded among 15 live fish in each sub-group at 2 mo. At 5 mo post-exposure to TAMs, the presence of blackened tail, head/jaw and 
spinal deformities were recorded for the surviving fish in each sub-group replicate aquaria. In addition, these same fish were examined for lesion scores, myxospore counts per half head and parasite genome equivalents by TaqMan (quantitative PCR [qPCR]) with methods identical to those described by Hedrick et al. (1999) and Kelley et al. (2004). Certain replicate sub-groups had fewer than 5 fish at 5 mo due to mortality experienced between 3 and 5 mo post-exposure. Among fish that died during the experiment, those that were more freshly dead were examined for evidence of external parasites by skin and gill scrapings and for internal bacteria by streaking of blood and trypticase soy agar plates. In addition, possible mortality due to whirling disease was assessed from clinical signs, and from analyses of selected fish $(\mathrm{n}=4)$ for microscopic lesions, amounts of Myxobolus cerebralis DNA, and myxospore counts as described above. Statistical analyses for differences between treatments, and between treatments and controls were not conducted because all metrics for evaluating whirling disease were negative in all of the treatment groups.

\section{RESULTS AND DISCUSSION}

All doses of UV tested were effective in inactivating the TAMs of Myxobolus cerebralis as evaluated by exposures of juvenile rainbow trout. There was no evidence of clinical disease among fish receiving UVtreated TAMs, and analyses of fish that died during the study period or that were sampled at 5 mo postexposure by qPCR, by histology (lesion severity) or by pepsin trypsin digest (PTD) analyses (myxospore counts) were all negative. In contrast, rainbow trout receiving the same levels of TAMs not treated with UV, experienced clinical disease and had high qPCR levels, lesion severity scores and myxospore counts. These results indicate that $\mathrm{UV}$ doses as low as $40 \mathrm{~mJ} \mathrm{~cm}^{-2}$ at the parasite levels tested are sufficient to inactivate the waterborne stages of $M$. cerebralis.

\section{Mortality}

A total of 17 fish died between 3 and 5 mo postexposure and it was necessary to determine whether whirling disease was the cause of death. All of the dead fish lacked clinical signs of the disease. The pattern of deaths across the treatments was consistent with non-whirling disease mortality: there were 4 deaths from a negative control group, none from the positive control groups, and the remainder from a variety of UV-treatment groups. Five fish were all from a single sub-group replicate receiving TAMs

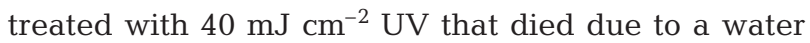
supply failure to this aquarium. Four of the 13 fish from UV-treatment groups were analyzed for the presence of microscopic lesions, myxospore counts and qPCR. All qPCR results were negative for Мyхоbolus cerebralis, and no lesions or myxospores were found. We used standard necropsy procedures to determine whether other microbial pathogens were involved in the mortality. There was no evidence for external parasites or bacterial pathogens in skin and gill scrapings or upon bacteriological media streaked with kidney tissue from a total of 5 fish deemed sufficiently fresh for analysis. Although the deaths could not be attributed to specific causes, the fact that all tests for $M$. cerebralis were negative indicates that the particular parasite was not involved in the mortality observed between 3 and 5 mo post-exposure.

\section{Measures of infectivity in the control groups}

All tests for the presence of Myxobolus cerebralis verified that the negative control groups were parasite free. Evidence included the absence of clinical signs of whirling disease, $M$. cerebralis DNA, microscopic lesions and myxospores. In contrast, nearly all the positive controls or fish receiving the same level of TAMs not treated with UV developed clinical signs of whirling disease (Table 1), and all fish examined at 5 mo post-exposure had severe lesion scores of 4 or 5 out of a maximum of 5 (Table 2), high myxospore counts averaging $10^{5.9}$ per half head (Table 2), and levels of $M$. cerebralis DNA with a mean of $10^{7.3}$ genome equivalents per $10^{6}$ trout cells (Table 2). These measures of infection among fish in the positive/procedural control group confirmed that the TAMs were viable, the fish were susceptible to infection, and procedures (stirring) inherent to the irradiation process did not reduce the viability of the TAMs.

\section{Measures of infectivity in UV treatment groups}

In the UV dose-response series, no clinical signs of whirling disease (whirling, black tail, head or jaw or spinal deformities) were observed for any of the fish in any of the treatments at any point during the 5 mo time course (Table 1). All fish examined at 5 mo post-exposure from all of the UV-treatment groups had lesion scores of zero (Table 2), myxospore counts of zero (Table 2), and were PCR-negative for Myxobolus cerebralis DNA (Table 2). All the UV doses from 40 to $160 \mathrm{~mJ} \mathrm{~cm}^{-2}$ were completely effective in preventing whirling disease in rainbow trout exposed to high challenge concentration of TAMs $\left(1000 \mathrm{fish}^{-1}\right)$. 
Table 1. Oncorhynchus mykiss. Effects of selected doses of UV irradiation on the infectivity of waterborne infective stages (triactinomyxon stages: TAMs) of Myxobolus cerebralis for juvenile rainbow trout. Replicate groups (Rep) of fish were held in $15^{\circ} \mathrm{C}$ water for 5 mo following exposure to the parasite. Numbers of fish in each treatment group exhibiting various clinical signs of whirling disease at 2 and 5 mo are reported. Observations were not recorded in all cases either when clinical signs would not be expected at these times after exposure (ne: not examined) or when none were available for analysis (na)

\begin{tabular}{|c|c|c|c|c|c|c|c|c|c|}
\hline \multicolumn{2}{|c|}{-Treatment -} & & & \multicolumn{4}{|c|}{ Clinical signs } & \multirow{2}{*}{\multicolumn{2}{|c|}{ Spinal deformity }} \\
\hline TAMs fish ${ }^{-1}$ & UV dose & \multicolumn{2}{|c|}{ Whirling } & \multicolumn{2}{|c|}{ Black tail } & \multicolumn{2}{|c|}{ Head/jaw deformity } & & \\
\hline & $\left(\mathrm{mJ} \mathrm{cm}^{-2}\right)$ & Rep 1 & Rep 2 & Rep 1 & Rep 2 & Rep 1 & Rep 2 & Rep 1 & Rep 2 \\
\hline \multicolumn{10}{|c|}{2 mo post-exposure } \\
\hline 0 & 0 & $0 / 15$ & $0 / 15$ & $0 / 15$ & $0 / 15$ & ne & ne & ne & ne \\
\hline 1000 & 0 & $12 / 15$ & $13 / 15$ & $14 / 15$ & $13 / 15$ & ne & ne & ne & ne \\
\hline 1000 & 40 & $0 / 15$ & $0 / 15$ & $0 / 15$ & $0 / 15$ & ne & ne & ne & ne \\
\hline 1000 & 80 & $0 / 15$ & $0 / 15$ & $0 / 15$ & $0 / 15$ & ne & ne & ne & ne \\
\hline 1000 & 120 & $0 / 15$ & $0 / 15$ & $0 / 15$ & $0 / 15$ & ne & ne & ne & ne \\
\hline 1000 & 160 & $0 / 15$ & $0 / 15$ & $0 / 15$ & $0 / 15$ & ne & ne & ne & ne \\
\hline \multicolumn{10}{|c|}{5 mo post-exposure } \\
\hline 0 & 0 & ne & ne & $0 / 5$ & $0 / 1$ & $0 / 5$ & $0 / 1$ & $0 / 5$ & $0 / 1$ \\
\hline 1000 & 0 & ne & ne & $5 / 5$ & $5 / 5$ & $4 / 5$ & $4 / 5$ & $5 / 5$ & $3 / 5$ \\
\hline 1000 & 40 & ne & ne & na & $0 / 2$ & na & $0 / 2$ & na & $0 / 2$ \\
\hline 1000 & 80 & ne & ne & $0 / 4$ & $0 / 5$ & $0 / 4$ & $0 / 5$ & $0 / 4$ & $0 / 5$ \\
\hline 1000 & 120 & ne & ne & $0 / 5$ & $0 / 3$ & $0 / 5$ & $0 / 3$ & $0 / 5$ & $0 / 3$ \\
\hline 1000 & 160 & ne & ne & $0 / 4$ & $0 / 4$ & $0 / 4$ & $0 / 4$ & $0 / 4$ & $0 / 4$ \\
\hline
\end{tabular}

Table 2. Oncorhynchus mykiss. Effects (mean values and SE) of selected doses of UV irradiation on the infectivity of waterborne infective stages (TAMs) of Myxobolus cerebralis for juvenile rainbow trout. Replicate groups (Rep) were held in $15^{\circ} \mathrm{C}$ water for 5 mo following exposure to the parasite and then 5 fish from each replicate, except where noted, were examined for severity of microscopic lesions $(0=$ uninfected to $5=$ heavily infected), concentrations of myxospores in the cranium, and parasite numbers based upon genome equivalents per $10^{6}$ host cells by quantitative PCR (qPCR) analyses. Results are absent from replicate groups where fish were no longer available for analysis (na) at 5 mo

\begin{tabular}{|c|c|c|c|c|c|c|c|}
\hline \multicolumn{2}{|c|}{$\longrightarrow$ Treatment $\longrightarrow$} & \multicolumn{2}{|c|}{ Lesion scores $(0-5)$} & \multicolumn{2}{|c|}{ Spore counts $\left(\log _{10}\right)$} & \multirow{2}{*}{\multicolumn{2}{|c|}{$\begin{array}{l}\text { Parasite genome } \\
\text { equiv. }\left(\log _{10}\right)\end{array}$}} \\
\hline TAMs fish ${ }^{-1}$ & $\begin{array}{l}\text { UV dose } \\
\left(\mathrm{mJ} \mathrm{cm} \mathrm{cm}^{-2}\right)\end{array}$ & Rep 1 & Rep 2 & Rep 1 & Rep 2 & & \\
\hline 0 & 0 & 0 & 0 & 0 & 0 & 0 & 0 \\
\hline 1000 & 0 & $4.0(0)$ & $4.4(0.6)$ & $5.9(0)$ & $5.9(0)$ & $6.8(0.2)$ & $7.8(0.5)$ \\
\hline 1000 & 40 & na & $0(0)$ & na & $0(0)$ & na & $0(0)$ \\
\hline 1000 & 80 & $0(0)$ & $0(0)$ & $0(0)$ & $0(0)$ & $0(0)$ & $0(0)$ \\
\hline 1000 & 120 & $0(0)$ & $0(0)^{\mathrm{a}}$ & $0(0)$ & $0(0)^{\mathrm{a}}$ & $0(0)$ & $0(0)^{\mathrm{a}}$ \\
\hline 1000 & 160 & $0(0)^{b}$ & $0(0)^{b}$ & $0(0)^{b}$ & $0(0)^{b}$ & $0(0)^{b}$ & $0(0)^{b}$ \\
\hline
\end{tabular}

\section{Comparisons to prior studies and applications of UV}

Studies by Hoffman $(1974,1975)$ and Hedrick et al. (2000) have shown UV to be effective at preventing whirling disease. Hedrick et al. (2000) demonstrated that rainbow trout exposed to TAMs irradiated at very high UV doses of $4000 \mathrm{~mJ} \mathrm{~cm}^{-2}$ were kept free of whirling disease. This study used a device that could only provide high UV doses because it had been designed for Cryptosporidium oocyst inactivation, which at the time was reported to require high UV doses. In the same study, complete inactivation of TAMs in static collimated beam exposures was shown at lower UV doses (1300 $\left.\mathrm{mJ} \mathrm{cm}^{-2}\right)$ as evaluated by vital staining. Since that work, vital staining has been shown to severely overestimate UV dose requirements for Cryptosporidium. Very low UV doses were found to inactivate the parasite when evaluated by infectivity (Bukhari et al. 1999), compared to earlier work suggesting high UV dose requirements when vital staining was used to evaluate UV efficacy (Campbell et al. 1995). Work on the parasite Giardia similarly found low UV doses to be effective when evaluated by infectivity (Craik et al. 2000, Linden et al. 2002). The current study confirms that for the parasite Myxobolus cerebralis, UV doses as low as $40 \mathrm{~mJ}$ 
$\mathrm{cm}^{-2}$ were sufficient to completely inactivate infectivity for rainbow trout under the conditions described. Hoffman $(1974,1975)$ also found UV to be effective in preventing whirling disease in rainbow trout. However, at the time of that pioneering work, the waterborne TAMs were not known and thus neither the challenge levels nor UV doses could be calculated accurately. Since the studies of Hoffman $(1974,1975)$, UV dose calculations for flow-through UV systems have been shown to typically overestimate actual UV doses when compared to more accurate determinations with a laboratory collimated beam test using a NIST-traceable radiometer (Petri \& Olson 2002). Our study confirms that the calculated UV doses of Hoffman $(1974,1975)$ were likely in the correct range, as we show complete protection against whirling disease at UV doses as low as $40 \mathrm{~mJ} \mathrm{~cm}^{-2}$. Hoffman (1974) showed that complete protection occurred at

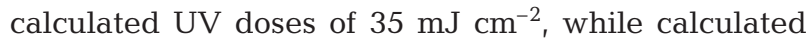
UV doses of $27.7 \mathrm{~mJ} \mathrm{~cm}^{-2}$ did not provide complete protection (Hoffman 1975). In contrast to the latter 2 studies, we have found that the threshold for complete inactivation of TAMs occurs at even lower doses, i.e. between 10 and $20 \mathrm{~mJ} \mathrm{~cm}^{-2}$, as assessed by infectivity trials with rainbow trout (authors' unpubl. results).

The concentrations of TAMs of Myxobolus cerebralis which are apt to be present in hatchery water supplies are best evaluated from filtration studies of natural waters (Thompson \& Nehring 2003, P. Reno pers. comm.). These studies indicate that concentrations of TAMs ranged from undetectable to 25 to 50 TAMs $^{-1}$. Considering water flows and fish numbers present in trout hatcheries, ambient levels of TAMs fish ${ }^{-1}$ over a $1 \mathrm{~h}$ period would unlikely exceed 0.3 to 3 , several thousand and several hundred-fold less than the levels of TAMs used in our experimental trials. A key difference between laboratory and natural exposures is that the former are static while the latter are continuous, and thus cumulative doses of TAMs may need to be considered. However, under conditions of continuous water treatments with UV, levels of TAMs present at any one point in time will be significantly less than 1000 TAMs fish $^{-1}$, a concentration found to be completely inactivated in the static challenges of rainbow trout in our study. Therefore, a UV dose continuously maintained

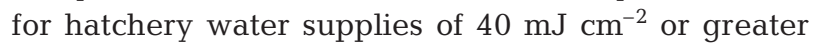
should be highly effective in preventing whirling disease.

In conclusion, the doses of UV required to inactivate the waterborne infective stages of Myxobolus cerebralis are considerably lower than those described in the prior work of Hedrick et al. (2000), and consistent with the UV doses recommended by Hoffman (1974, 1975). Doses of $40 \mathrm{~mJ} \mathrm{~cm}^{-2}$ are cost effective for the treatment of large water supplies to fish rearing facilities, and thus, UV may become a more broadly used means of water disinfection in areas where the waterborne infective stages of $M$. cerebralis are found.

Acknowledgements. Contributors to this work included Mr. Mark Sampson of Water Control Corporation and Mr. Gary Vanderlaan of Trojan Technologies.

\section{LITERATURE CITED}

Anonymous (1997) UV disinfection devices for drinking water supply requirements and testing. Deutsche Vereinigung des Gas- und Wasserfaches (DVGW), Bonn

Anonymous (2001) ÖNORM M 5873-1 Plants for the disinfection of water using ultraviolet radiation: requirements and testing. Part 1. Low pressure mercury lamp plants. Österreichisches Normungsinstitut, Vienna

Anonymous (2003a) ÖNORM M 5873-2 Plants for the disinfection of water using ultraviolet radiation: requirements and testing. Part 2. Medium pressure mercury lamp plants. Österreichisches Normungsinstitut, Vienna

Anonymous (2003b) Ultraviolet disinfection guidelines for drinking water and water reuse, 2nd edn. National Water Research Institute, Fountain Valley, CA

Anonymous (2006) National primary drinking water regulations: long-term 2 enhanced surface water treatment rule. United States Environmental Protection Agency, Office of Water, Washington, DC

Bolton JR, Linden KG (2003) Standardization of methods for fluence (UV dose) determination in bench-scale UV experiments. J Environ Eng 129:209-215

Bukhari Z, Hargy TM, Bolton JR, Dussert B, Clancy JL (1999) Inactivation of Cryptosporidium parvum oocysts using medium-pressure ultraviolet light. J Am Water Works Assoc 91:86-94

Campbell AT, Robertson LJ, Snowball MR, Smith HV (1995) Inactivation of oocysts of Cryptosporidium parvum by ultraviolet irradiation. Water Res 29:2583-2586

Craik SA, Finch GR, Bolton JR, Belosevic M (2000) Inactivation of Giardia muris cysts using medium-pressure ultraviolet radiation in filtered drinking water. Water Res 34: 4325-4332

Hedrick RP, El-Matbouli M, Adkison MA, MacConnell E (1998) Whirling disease: re-emergence among wild trout. Immunol Rev 166:365-376

Hedrick RP, McDowell TS, Gay M, Marty GD, Georgiadis MP, MacConnell M (1999) Comparative susceptibility of rainbow trout Oncorhynchus mykiss and brown trout Salmo trutta to Myxobolus cerebralis, the cause of salmonid whirling disease. Dis Aquat Org 37:173-183

Hedrick RP, McDowell TS, Marty GD, Mukkatira K, Antonio DB, Andree KB, Bukhari Z, Clancy T (2000) Ultraviolet irradiation inactivates the waterborne infective stages of Myxobolus cerebralis: a treatment for hatchery water supplies. Dis Aquat Org 42:53-59

Hoffman GL (1970) Intercontinental and transcontinental dissemination and transfaunation of fish parasites with emphasis on whirling disease (Myxosoma cerebralis). In: Snieszko SF (ed) A symposium on diseases of fish and shellfishes. American Fisheries Society, Washington, DC, p 69-81

Hoffman GL (1974) Disinfection of contaminated water by ultraviolet irradiation, with and emphasis on whirling dis- 
ease (Myxosoma cerebralis) and its effect on fish. Trans Am Fish Soc 103:541-550

Hoffman GL (1975) Whirling disease (Myxosoma cerebralis) control with ultraviolet irradiation and effect on fish. J Wildl Dis 11:505-507

Hoffman GL (1990) Myxobolus cerebralis, a worldwide cause of salmonid whirling disease. J Aquat Anim Health 2: 30-37

Kelley GO, Zagmutt-Veraga FJ, Leutenegger CM, Mykelbust KA and 7 others (2004) Evaluation of five diagnostic methods for the detection and quantification of Myxobolus cerebralis. J Vet Diagn Inv 16:202-211

Linden KG, Shin GA, Faubert G, Cairns W, Sobsey MD (2002) UV Disinfection of Giardia lamblia cysts in water. Environ Sci Technol 36:2519-2522

Modin J (1998) Whirling disease in California: a review of its history, distribution, and impacts, 1965-1997. J Aquat Anim Health 10:132-142

Nehring RB, Walker PG (1996) Whirling disease in the wild: the new reality in the intermountain west. Fisheries (Bethesda) 21:28-32

Petri BM, Olson D (2002) Bioassay validation of compu-

Editorial responsibility: Dieter Steinhagen,

Hannover, Germany tational disinfection models used for UV reactor design and scale-up. Water Environment Federation Disinfection 2002 Specialty Conference, St. Petersburg, Florida, February 17-20, 2002. CD-ROM. Water Environment Federation, Alexandria, VA

Qian S, Donnelly M, Schmelling D, Messner M, Linden K, Cotton C (2004) Ultraviolet light inactivation of protozoa in drinking water: a Bayesian meta-analysis. Water Res 38(2): 317-326

Thompson KG, Nehring RB (2003) A simple technique used to filter and quantify the actinospore of Myxobolus cerebralis and determine its seasonal abundance in the Colorado River. J Aquat Anim Health 12:316-323

Vincent ER (1996) Whirling disease and wild trout: the Montana experience. Fisheries (Bethesda) 21:32-34

Wagner E (2002) Whirling disease prevention, control and management: a review. In: Bartholomew JL, Wilson JC (eds) Whirling disease: reviews and current topics. Amercian Fisheries Society, Bethesda, MD, p 217-225

Wolf K, Markiw ME (1984) Biology contravenes taxonomy in the Myxozoa: new discoveries show alternation of invertebrate and vertebrate hosts. Science 225:1449-1452

Submitted: May 15, 2006; Accepted: September 20, 2006 Proofs received from author(s): February 23, 2007 